\title{
Surprising high iron enrichment in hard dental tissues of rodents
}

\author{
Vesna Srot ${ }^{1}$, Ute Salzberger ${ }^{1}$, Birgit Bussmann ${ }^{1}$, Boštjan Pokorny ${ }^{2,3}$, Ida Jelenko ${ }^{2}$ and Peter A. van Aken ${ }^{1}$ \\ 1. Max Planck Institute for Intelligent Systems, Stuttgart Center for Electron Microscopy, Stuttgart, Germany \\ 2. ERICo Velenje, Ecological Research and Industrial Cooperation, Velenje, Slovenia \\ 3. Environmental Protection College, Velenje, Slovenia
}

Biominerals formed by living organisms display highly diverse composition and structure. Many of such biominerals are highly complex composite materials with excellent physical and mechanical properties $[1,2]$ that cannot be mimicked in the laboratory. These unique masterpiece architectures where organic matrix and crystalline or amorphous minerals are linked together are formed under conditions of moderate temperature, pressure and $\mathrm{pH}$.

Rodents possess long opposing pairs of through life continuously growing incisors, which are worn down by gnawing. The front surface of the incisors is enamel consisting of $96 \mathrm{wt} \%$ of inorganic material. The innermost part, softer dentine, forms the bulk of the teeth [3]. The surface of incisors of different rodent species shows characteristic orange-brown colour and is identified with the presence of iron [4]. Surface layer of rat's enamel characterized by electron microprobe analysis [5] showed that the amount of iron $(\mathrm{Fe})$ is $10-30 \mathrm{wt} \%$.

In this study, the microstructure and the chemical composition of incisors and molars of the feral coypu (Myocastor coypus Molina) were investigated in detail by using energy-dispersive X-ray spectroscopy (EDX) and electron energy-loss spectroscopy (EELS) combined with scanning transmission electron microscopy (STEM) imaging at high spatial as well as high energy resolution using VG HB501UX, Zeiss SESAM and Jeol ARM200F microscopes.

The layer with a variable thickness was uncovered on the outer surface of the incisors which has not been observed before in rodent teeth. An annular dark field (ADF)-STEM image of a cross-sectional view showing the interface between the Fe-rich surface layer (Fe-SL) and Fe-rich enamel (Fe-E) is presented in Figure 1a. Based on our observations and analytical measurements the amount of iron in this surface layer is much higher compared to the concentration values reported in the literature. Within the iron-rich surface layer we surprisingly detected multiple iron-containing varieties. Studies of the electronic structure suggest that iron is present in predominantly 3+ valence state. O-K energy-loss nearedge structures (ELNES) acquired from different positions within the Fe-SL suggests the presence of different intermixing levels between $\mathrm{Fe}$ phosphate and Fe oxide/hydroxide (Figure 1b). Based on our energy-filtered TEM (EFTEM) investigations we proved that the interface between the Fe-E and above lying Fe-SL is relatively rough (Figure 2).

In spite of the wide occurrence of iron in many living organisms, its function and incorporation is not unambiguously understood. Present discoveries will considerably enhance the understanding and function of $\mathrm{Fe}$ incorporation in hard dental tissues at the nanoscale level. 


\section{References:}

[1] UGK Wegst and MF Ashby, Philos Mag 84 (2004), 2167.

[2] AP Jackson and JFV Vincent, J Mater Sci 25 (1990), 3173.

[3] BA Niemec in "Small animal dental, oral \& maxillofacial disease" (2010), Manson Publishing Ltd, London.

[4] EV Pindborg JJ Pindborg and CM Plum, Acta Pharmacol 2 (1946), 294.

[5] A Halse, Archs Oral Biol 19 (1974), 7.
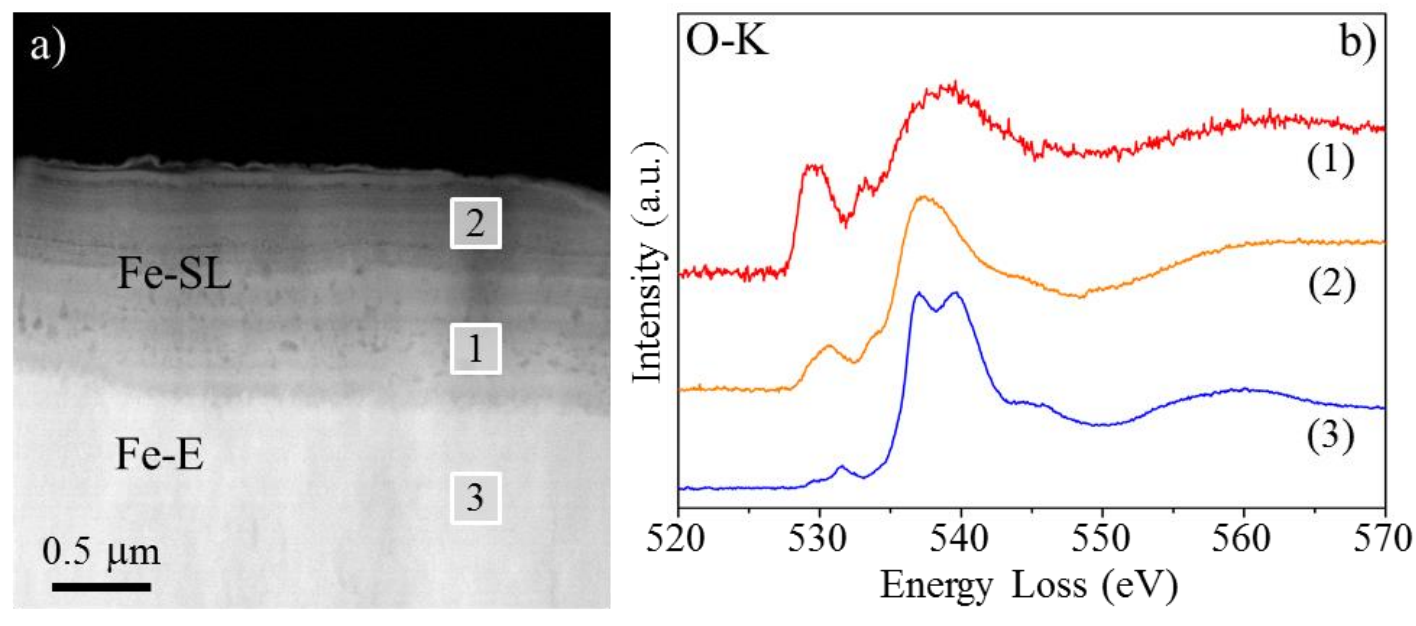

Figure 1. ADF-STEM image (a) of the interface between Fe-rich surface layer (Fe-SL) and Fe-rich enamel (Fe-E). O-K ionization edges acquired from positions marked in (a) are shown in (b). In Fe-SL different intermixing levels between Fe oxide/Fe hydroxide (spectrum 1) and Fe phosphate (spectrum 2) were observed. $\mathrm{O}-\mathrm{K}$ spectrum acquired from $\mathrm{Fe}-\mathrm{E}$ is shown in spectrum 3.
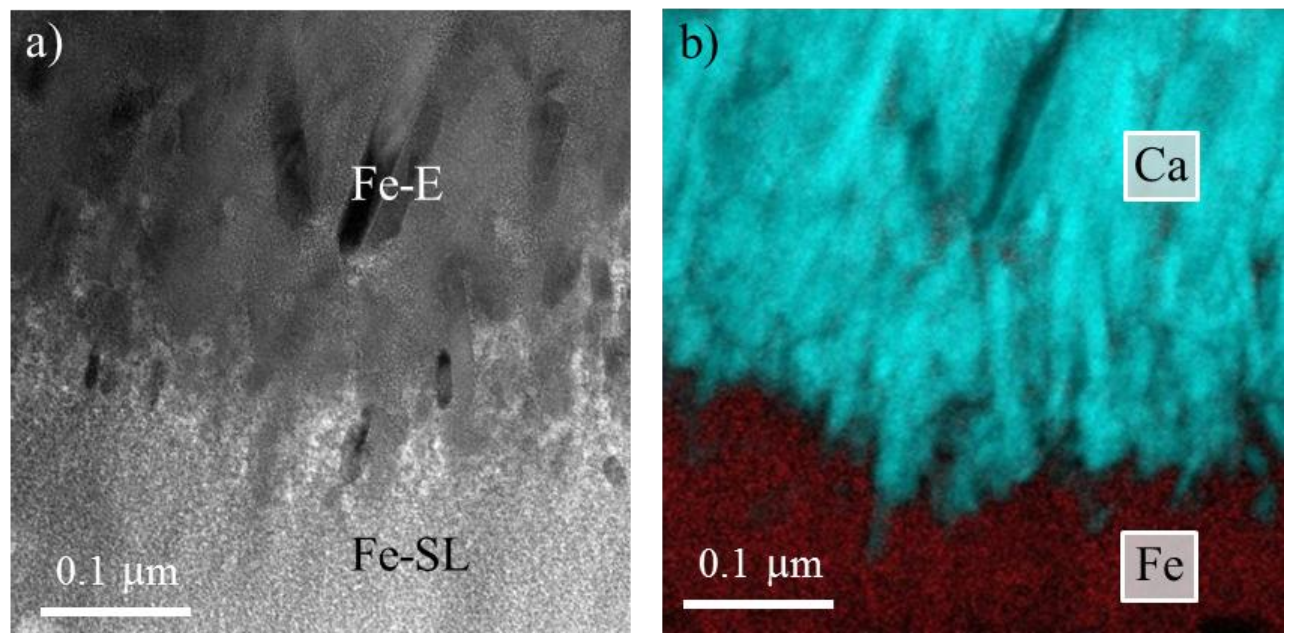

Figure 2. (a) Bright-field TEM image of the rough interface between Fe-SL and Fe-E. (b) Corresponding calcium $(\mathrm{Ca})$ and iron (Fe) EFTEM maps. 